\title{
Affluence and Objective Environmental Conditions: Evidence of Differences in Environmental Concern in Metropolitan Brazil
}

\author{
Raphael J Nawrotzki ${ }^{1}$, Gilvan Guedes ${ }^{2} \&$ Roberto L Carmo ${ }^{3}$ \\ ${ }^{1}$ Institute of Behavioral Science, CU Population Center, University of Colorado at Boulder, United States \\ ${ }^{2}$ Department of Demography, Center for Regional Urban Planning (CEDEPLAR), Federal University of Minas \\ Gerais, Brazil \\ ${ }^{3}$ Department of Demography, Population Studies Center (NEPO), University of Campinas, Brazil \\ Correspondence: Raphael J Nawrotzki, Institute of Behavioral Science, CU Population Center, University of \\ Colorado at Boulder, United States. E-mail: raphael.nawrotzki@colorado.edu
}

Received: November 10, 2013

doi:10.5539/jsd.v7n2p173

\author{
Accepted: February 24, 2014 Online Published: March 21, 2014 \\ URL: http://dx.doi.org/10.5539/jsd.v7n2p173
}

\begin{abstract}
In an age of climate change, researchers need to form a deepened understanding of the determinants of environmental concern, particularly in countries of emerging economies. This paper provides a region-specific investigation of the impact of socio-economic status (SES) and objective environmental conditions on environmental concern in urban Brazil. We make use of data collected from personal interviews of individuals living in the metropolitan areas of Baixada Santista and Campinas, in the larger São Paulo area. Results from multilevel regression models indicate that wealthier households are more environmentally concerned, as suggested by affluence and post-materialist hypotheses. However, we also observe that increasing environmental concern correlates with a decline in objective environmental conditions. Interactions between objective environmental conditions and SES reveal some intriguing relationships: Among poorer individuals, a decline in environmental conditions increases environmental concern as suggested by the objective problems hypothesis, while for the wealthy, a decline in environmental conditions is associated with lower levels of environmental concern.
\end{abstract}

Keywords: environmental concern, socio-economic status, metropolitan Brazil, affluence hypothesis, environmental conditions

\section{Introduction}

Industrialization and the related technological development have both benefitted and acted as a detriment to humanity. Development, particularly in urban areas, has substantially improved the living conditions and life-expectancy around the world (Uhlenberg, 2006). In contrast, development has also fostered environmental destruction and contributed substantially to the effect of global warming through an increase in Greenhouse Gas (GHG) emission (IPCC, 2007; Jessup, 2010). A global approach, in which all nations of the world, regardless of development status, are willing to change their energy production and consumption, is necessary to effectively address climate change (Nawrotzki, Diaconu, \& Pittman, 2009). To stabilize the GHG emission, numerous countries have pledged to tighten their environmental laws and regulations and curb $\mathrm{CO}_{2}$ emissions within the framework of the Kyoto Protocol and the Bali Action Plan (UNFCCC, 1998, 2008). At the macro-level, this commitment served as an important step, but effective change will come only if people at all levels within the social fabric plan to alter their consumption patterns and to make financial sacrifices in order to prevent further environmental degradation. To effectively support sustainable consumption patterns and to encourage environmentally friendly behavior, policy makers must understand the state of public environmental concern among different groups.

Individual's socio-economic status (SES) has far-reaching implications for environmental values, beliefs, attitudes, and behaviors (SES) (Franzen \& Meyer, 2010; Bayard \& Jolly, 2007; Meyer \& Liebe, 2010; Gelissen, 2007). In addition, some evidence shows that local environmental conditions directly impact environmental concern (Inglehart, 1995). However, most environmental concern studies originate in the U.S. or Western Europe (Jessup, 2010; Meyer \& Liebe, 2010; Marquart-Pyatt, 2008; Xiao \& Dunlap, 2007). Few of these studies 
use a collection of data for different countries made available by the International Social Survey Program (ISSP) (e.g., Franzen \& Meyer, 2010; Nawrotzki, 2012) or the World Value Survey (Kidd \& Lee, 1997), which also include certain Latin American countries. However, no analysis investigates the connection between SES and environmental concern for urban areas in any Latin American country.

Thus, we seek to answer the following three questions: 1) Are affluent households more concerned with the environment than low SES households in metropolitan Brazil?; 2) Do "objective" environmental conditions in metropolitan Brazil impact environmental concern?; 3) Is the relation between objective environmental conditions and environmental concern in metropolitan Brazil different for individuals of varying socioeconomic background?

\section{Conceptual Framing and Literature Review}

\subsection{Environmental Concern and Socioeconomic Status}

Explaining individual and cross national differences in environmental concern, based on socioeconomic status is rather difficult and is still a controversial issue in social science research (Franzen \& Meyer, 2010). The controversy began in the early 1990s (c.f., Dunlap \& York, 2008), but has not been resolved to date. Two schools of thought exist based on competing theories that vigorously defend their positions: Ronald Inglehart asserts his post-materialist value hypothesis, and Riley Dunlap argues his global environmentalism theory.

Inglehart (1995) proposed that environmental awareness and concern emerge as societies become more developed and affluent (c.f., Inglehart \& Baker, 2000). According to his theory, concern for quality-of-life-issues, such as free speech, liberty, and environmental protection (post-materialist values) arise only after individuals have met their more basic materialist needs (food, shelter, safety). The development of post-materialist values essentially represents a cohort phenomenon in which individuals raised under conditions of economic security express higher environmental concern (Kidd \& Lee, 1997). At the individual level, this relationship exists for advanced industrial societies (Drori \& Yuchtmann-Yaar, 2002; Kidd \& Lee, 1997).

Other researchers have built upon Inglehart's post-materialist hypothesis and designed the affluence or prosperity hypothesis (Diekmann \& Franzen, 1999; Drori \& Yuchtman-Yaar, 2002). This hypothesis assumes that environmental quality is not only a public good, but also a good for which the demand rises with the affluence of a certain individual. Environmental quality constitutes an amenity good that high SES individuals can more readily afford (Franzen \& Meyer, 2010). This hypothesis draws on traditional economic theory, suggesting that environmental concern is independent of preferences and post-materialist values. Rather, elasticity of demand, as a function of "unequal constraints (i.e. incomes)", emerges as a concern which impacts the ability to afford pro-environmental attitudes and behavior (Meyer \& Liebe, 2010). Regardless of the underlying mechanisms, numerous studies at the individual and national level show a positive association between SES measures and environmental concern (Gelissen, 2007; Marquart-Pyatt, 2008; Franzen \& Meyer, 2010; Franzen, 2003; Kemmelmeier, Krol, \& Kim, 2002; Nawrotzki, 2012).

Dunlap and Mertig (1997) and Brechin and Kempton (1994) have challenged this reasoning by arguing that environmentalism remains independent of wealth and SES. They demonstrate that environmentalism is present in both wealthy and poor countries alike, and therefore argue that concern for the environment is not a product of affluence and post-materialist cultural shift, but instead, a result of multiple sources (e.g., social perceptions, local histories and environmental realities, international relationships and influences, unique cultural and structural features of particular regions (Brechin, 1999). More recently, Dunlap and York (2008) have used empirical findings from the Health of the Planet survey to provide evidence that less developed nations indicated higher levels of pro environmentalism. Ultimately they argue that environmental activism and public support for environmental protection have become global phenomena and are not limited to the wealthy nations of the world. This theory has become known as the global environmentalism (GE) hypothesis.

Other scholars have criticized the global environmentalism hypothesis because it is based largely on country-level findings and might not appropriately reflect individual-level differences between social classes within a particular nation (c.f., Kidd \& Lee, 1997). However, in line with the GE hypothesis, some individual-level studies seem to indicate that low SES individuals and minorities are similarly concerned about the environment (Uyeki \& Holland, 2000; Kahn, 2002; Whittaker, Segura, \& Bowler, 2005). For example, Adeola (2004) found that African Americans and other minorities of lower SES within the United States are relatively more concerned with environmental problems than white upper-middle class individuals (see also Mohai \& Bryant, 1998). Other studies more broadly confirm that low SES individuals are more environmentally concerned than high SES individuals (Uyeki \& Holland, 2000). They explain that the poor and ethnic minorities usually reside in the least desired living spaces in the urban areas, which are often close to industry, commerce, 
heavy traffic, and depots for garbage collection and disposal. These experiences sensitize the poor and minority groups to the environment and create more concern for the environment, even if they feel powerless to change their situation (Uyeki \& Holland, 2000). A large body of literature, based upon the environmental justice (EJ) framework, explores the environmental burden experienced by the poor and minority groups (Brulle \& Pellow, 2006; Shriver \& Webb, 2009; Grineski et al., 2010). These groups seem to develop environmental awareness and concern based on the disproportionate burden of environmental disamenities in their neighborhoods (Mohai \& Bryant, 1998), in the absence of prosperity, or post-materialist value orientations.

Finally, other studies conducted in Brazil (Guedes et al., 2012; Guedes \& Carmo, 2012) suggest that individuals from different SES backgrounds are equally likely to be concerned and exercise environmental actions. Poorer individuals equally engage in pro-environmental behaviors but are more likely to participate in public actions (e.g., collective actions, community gardens, protests against companies that pollute) than private ones (e.g., recycling, buying organic products). This may reflect the effect of budget constraints on the poor who revert to alternative channels that do not require money (e.g., protesting) to express their concern for the environment (Guedes et al., 2012).

\subsection{Environmental Concern and "Objective" Environmental Conditions}

Concerns about the environment are, to a considerable degree, a function of actual environmental conditions (Abramson, 1997; Abramson \& Inglehart, 1995). Rohrschneider (1990) has shown that the physical characteristics of the environment impact the development of attitudes toward environmental protection (Rohrschneider, 1990). Inglehart (1995) used data from the World Value Survey, to investigate the correlation between prosperity and environmental concern, and discovered that the less affluent citizens of some developing nations also displayed high levels of environmental concern. In response to this finding, which appeared to contradict his post-materialist hypothesis, Inglehart formulated a two-factor explanation, the "objective problems and subjective values" (OPSV) hypothesis. According to this hypothesis, members of wealthy societies embrace pro-environmental attitudes in the process of adopting post-materialistic values under conditions of material affluence. In poor countries, on the other hand, citizens face pressing regional environmental problems, such as pollution, flooding, lack of sanitation, and lack of access to clean water, leading to the development of heightened environmental awareness and concern. Guha and Martinez-Alier (1997, p. xxi) have made essentially the same distinction with their "empty-belly" environmentalism of the South and "full-stomach" environmentalism of the North theory.

Brechin (1999) and Dunlap and York (2008, p. 536) have criticized the OPSV hypothesis as "nonfalsifiable" and "grossly simplistic", and deem it inadequate to fully understand the diverse and complex source of environmentalism across the world. However, this evaluation references the OPSV hypothesis as a whole, whereas the objective problem part is largely considered to be valid, even by critics such as Brechin (1999). Moreover, recent research has confirmed the existence of the postulated negative association between local environmental conditions and concern (Hunter, Strife, \& Twine, 2010). However, Dunlap and York (2008, p. 537) caution that even the straight-forward effect of objective problems on environmental concern is not a simple "stimulus-response phenomenon." Rather, the multifaceted influence of media, science, government agencies, education, and environmental organizations mediates the relationship (e.g., Frank, 1997; Frank et al., 1999).

The prior paragraphs outline the debate regarding the impact of socio-economic status and objective environmental conditions on environmental concern. Although some scholars have attempted to solve this empirical puzzle (e.g., Pampel \& Hunter, 2012; Nawrotzki \& Pampel, 2012), the debate remains contentious. In this paper, we investigate which theory will most appropriately predict environmental concern in metropolitan Brazil.

\section{Research Site and Data Collection}

We chose urban Brazil for our investigation of the determinants of environmental concern. Brazil has a booming economy, which has led the country to become the largest emitter of GHGs among all Latin American countries (ECLAC, 2009). The state of development and associated pollution problems are likely to impact environmental concern. Scholars characterize Brazil as both, environmentally concerned (Abramson, 1997; Schultz et al., 2005) and environmentally indifferent (Bechtel, Verdugo, \& Pinheiro, 1999). These opposing findings may reflect regional differences in pressing environmental problems, as well as the timing of public discussion of environmental changes in Brazil, such as industrial pollution, biofuel production, and deforestation in the Amazon (Crespo, 2003). 
Rather than investigating Brazil's overall state of environmental concern, we focus our attention on urban areas for three reasons: (1) Urban areas emit more GHG than rural areas (Rice \& Bostrom, 2011), and thus an increase in pro-environmental concern and behavior might substantially impact the overall emission pattern. (2) Individuals residing in urban areas are more politically active compared to people in rural areas (c.f., Paczynska, 2005). (3) Brazil is highly urbanized; $74 \%$ of the country was classified as urban in 2007 (90\% for the State of São Paulo) (IBGE, 2013). To trigger countrywide social change, knowledge about the state of environmental concern among this politically active and demographically relevant group of urban dwellers is important.

The Núcleo de Estudos de População (Population Studies Center) (NEPO) of the State University of Campinas (UNICAMP), collected the data for the present analysis as part of the project Dinâmica Intrametropolitana e Vulnerabilidade Sócio-demográfica das Metrópoles do Interior Paulista: Campinas e Santos (Intrametropolitan Dynamics and Sociodemographic Vulnerability of Campinas and Baixada Santista Metropolitan Areas). NEPO collected data on a representative sample of the population residing in the Campinas Metropolitan Area - CMA (Figure 1a) and the Baixada Santista Metropolitan Area - BSMA (Figure 1b). The probabilistic survey employed a complex two-stage sampling design with stratification by vulnerability zones (see Cunha et al., 2006, for a more detailed discussion of the sampling method).

To allow for stratification, vulnerability zones were generated. A factor analysis was employed with variables containing information on physical capital, human capital, and social capital, derived from the year 2000 Brazilian Demographic Census (BDC). Six factors were identified: two for physical capital, one for human capital, and two for social capital. The variables loading highest on each factor were combined to generate standardized factor scores (ranging from 0 to 1 ). The factor scores were aggregated to "weighting areas," which represent a combination of census tracts as defined by the BDC. The Baixada Santista Metropolitan Area (BSMA) is comprised of 78 weighting areas, while the Campinas Metropolitan Area (CMA) contains 49 weighting areas. The factor scores were subsequently used within a cluster analysis to generate clusters of weighting areas (vulnerability zones) with similar socio-demographic and physical characteristics. The factor and cluster analyses were performed for each metropolitan area separately, resulting in three and six vulnerability zones for BSMA and CMA, respectively.

The selection of the households to be interviewed followed two stages: In the first stage census tracts, as the primary sampling unit (PSU), were randomly selected from within each vulnerability zone (stratum), using a probability of selection proportional to the size of the respective census tract (number of households in the census tract). In the second stage, a list of households within each selected census tract was compiled and households, representing the secondary sampling unit (SSU), were randomly selected from this list for inclusion in the survey. On average, 15 households were interviewed in each selected census tract, resulting in about 523 and 300 questionnaires applied for each vulnerability zone in BSMA and CMA, respectively.

With seven modules, the questionnaire was designed to mainly reflect household-level decisions and characteristics, although some individual-level questions were asked (mainly socio-demographic characteristics of household members) (Note 1). The survey data was collected through personal interviews in the second half of 2007 (Cunha et al., 2006). Our analytical sample includes 3,370 households (CMA: $n=1,801$; BSMA: $\mathrm{n}=1,569)$.

In 2000, the Brazilian government established the Campinas Metropolitan Area (CMA), comprising 19 municipalities (see Figure 1, panel a). In 2010, CMA had an estimated population of 2.8 million inhabitants, 97.5\% living in urban areas. CMA is the third main economic area in Brazil, after São Paulo and Rio de Janeiro. Specifically air pollution threatens residents of CMA originating from three main sources: (1) a large oil refinery and petrochemical industrial complex in the municipality of Paulínia; (2) heavy car and truck traffic from two of the most important Brazilian roads (Anahnguera \& Bandeirantes), and (3) the burning of sugar-cane plantations to produce sugar or ethanol. 

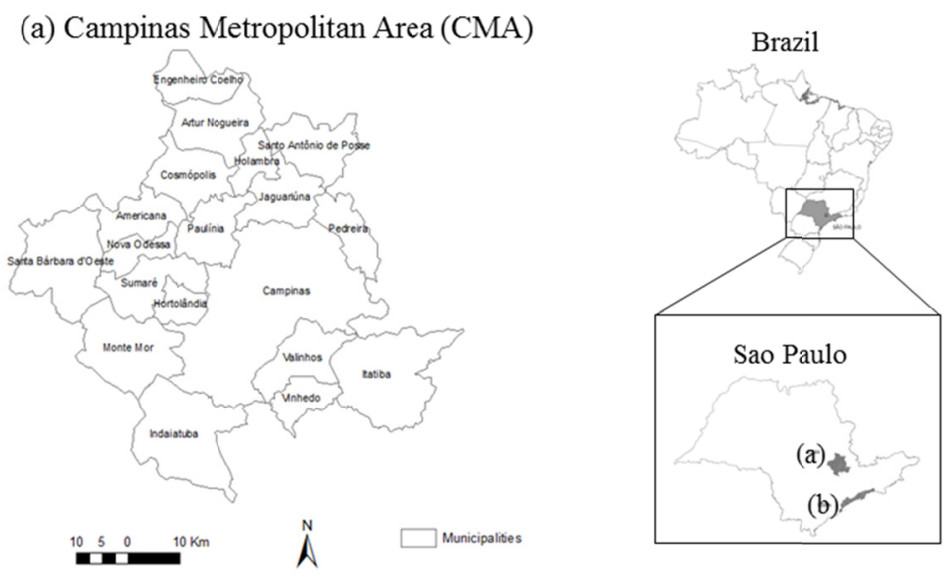

(b) Baixada Santista Metropolitan Area (BSMA)
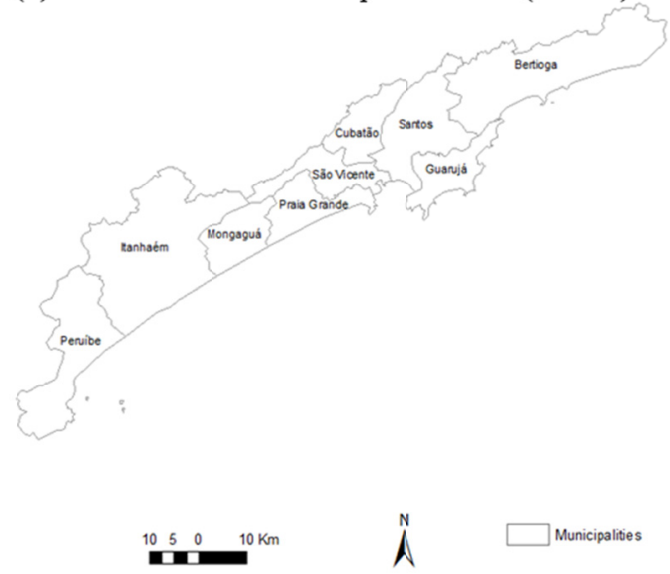

Figure 1. Geographic location of Campinas metropolitan area (CMA) and Baixada Santista metropolitan area (BSMA) in São Paulo, Brazil

The Brazilian government officially recognized the Baixada Santista Metropolitan Area (BSMA) in 1996, comprising nine municipalities (see Figure 1, panel b). In 2010, BSMA had an estimated population of 1.6 million inhabitants, with $99.7 \%$ of its residents living in urban areas. In contrast to CMA, BSMA is a coastal zone bordered by a protected area Serra do Mar (Mountain Range of the Sea). BSMA's topography represents a physical barrier to the horizontal expansion of its municipalities, influencing the level of environmental vulnerability. The flat strip between the Atlantic Ocean and the Serra do Mar contains a large number of streams and swamps. Due to the high level of unplanned urbanization and limited sanitation service capacity, water quality is of constant concern for the residents of BSMA. In addition, intense rainfalls throughout the year cause sewer spillovers and clogging of storm drains, with adverse effects on the water situation.

\section{Variable Construction}

\subsection{Outcome Variable}

As the primary outcome variable, we generated a standardized environmental concern scale based on four available items in our dataset (see Table 1) (Note 2). These questions were borrowed from previous questionnaires applied nationally by the Brazilian Ministry of the Environment (Crespo, 2003). These items touch on different concepts that, in sum, shape a person's attitude towards the environment. The items capture the general concern about global warming, the trade-off between environmental protection and job creation, concern about limitations of natural resources, and a more general perception of nature as a sacred entity. Environmental concern scales, with varying numbers of items, have been widely used as outcome variables in studies of environmental concern (Franzen \& Meyer, 2010; Gelissen, 2007; Franzen, 2003; Kemmelmeier, Krol, \& Kim, 2002; Nawrotzki, 2012). We also estimate models for each outcome variable individually. This allows us to base our conclusions on results from both, individual-item models and additive scale models, with 
emphasis on the latter one. Table 1 lists the questions and answer options for relevant items employed in this study.

Table 1. Survey items used for the analysis of the relationship between SES, objective environmental conditions, and environmental concern

\begin{tabular}{|c|c|}
\hline Survey Item & Response options \\
\hline \multicolumn{2}{|l|}{ Environmental concern } \\
\hline In your opinion, how serious is the threat of global warming? & Very serious to not serious at all \\
\hline I would accept more pollution if it created more jobs. & Agree / Disagree \\
\hline $\begin{array}{l}\text { Brazil has an abundant natural endowment; resource use does } \\
\text { not need to be controlled. }\end{array}$ & Agree / Disagree \\
\hline $\begin{array}{l}\text { Nature is sacred and human beings should not interfere with it. } \\
\text { Household environmental conditions (HEC) }\end{array}$ & Agree / Disagree \\
\hline $\begin{array}{l}\text { Regarding the immediate surroundings of your house, please } \\
\text { indicate how serious... }\end{array}$ & Very serious to not serious at all \\
\hline \multicolumn{2}{|l|}{...the problem of contamination is. } \\
\hline \multicolumn{2}{|l|}{...the problem of lack of accessibility to green spaces is. } \\
\hline \multicolumn{2}{|l|}{...the problem of a lack of water supply and drainage is. } \\
\hline \multicolumn{2}{|l|}{...the problem of a lack of garbage collection is. } \\
\hline \multicolumn{2}{|l|}{...the problems with insects and rodents are. } \\
\hline \multicolumn{2}{|l|}{...the problems of overgrown areas and denuded lands are. } \\
\hline \multicolumn{2}{|l|}{ Community environmental conditions (CEC) } \\
\hline $\begin{array}{l}\text { How would you describe the street conditions in your } \\
\text { neighborhood? }\end{array}$ & $\begin{array}{l}\text { Paved (good conditions) to unpaved } \\
\text { (irregular) }\end{array}$ \\
\hline Do the streets in your neighborhood have curbs and gutters? & Yes / No \\
\hline Do the streets in your neighborhood have sidewalks? & Yes / No \\
\hline $\begin{array}{l}\text { How would you describe the type of sewage collection and } \\
\text { disposal in your neighborhood? }\end{array}$ & $\begin{array}{l}\text { Public sewage collection system to } \\
\text { discharging directly into rivers }\end{array}$ \\
\hline
\end{tabular}

Note: A factor analysis demonstrated that items listed under household environmental conditions loaded on a different factor (factor 2), compared to items listed under community environmental conditions (factor 1).

Source: Data from Projeto Vulnerabilidade (NEPO/Unicamp).

Summary statistics (Table 2) reveal a high level of environmental concern among respondents. For example, of the three items, which use an agree/disagree response (e.g., pollution for jobs, control of natural resources, nature is sacred), $95 \%, 92 \%$, and $95 \%$ of survey participants answered in favor of the environment. The high levels of environmental concern can be attributed, in part, to the reference date of the survey, which followed the highly publicized release of the $4^{\text {th }}$ assessment report of the International Panel on Climate Change (IPCC, 2007).

\subsection{Predictor Variables}

The main variables of interest included a measure of socioeconomic status (SES) and two measures of "objective" environmental conditions. The SES variable constitutes a weighted composite measure based on information regarding the possession of certain durable physical assets (e.g., television, radio, automobile, vacuum cleaner, washing machine, VCR/DVD player, refrigerator, freezer), the quality of the housing unit (e.g., bathroom), the usage of certain services (e.g., maid), and the educational level of the household head (years of schooling). Such composites frequently serve as reliable measures to reflect households' socioeconomic status (Gwatkin et al., 2007; Mberu, 2006; Nawrotzki, Hunter, \& Dickinson, 2012). The composite measure was constructed according to the classification scheme suggested by the Brazilian Association of Research Companies (ABEP, 2008). To obtain a sufficient number of cases for each category, we merged both, high and 
very high SES classes, as well as low and very low SES classes, resulting in the following three classes: low SES (ABEP classes D\&E), medium SES (ABEP class C), and high SES (ABEP class A\&B).

To measure "objective" environmental conditions, we performed a factor analysis on ten available items. Using a varimax rotated factor matrix with a threshold of 0.40 , we identified two major categories; we used the items for each category to construct separate standardized scales. The first scale included six items inquiring about the environmental conditions in close proximity to respondents' residency. As such, we use the term Household Environmental Conditions (HEC, Cronbach's alpha=.746) scale to refer to this composite measure. Environmental conditions that these items address include problems with contamination, garbage collection, insects, rodents, and availability of green spaces (see Table 1).

The four items, with high loadings on the second factor, form the Community Environmental Conditions (CEC, Cronbach's alpha $=.902)$ scale. These items largely reflect the quality of the available infrastructure at the community level, and include measures for the quality of the street (including the availability of curb, gutter, sidewalks), and the type of sewage disposal (see Table 1). For a better representation of true "community" environmental conditions, we aggregated the CEC scale to the census tract level (computing the mean).

\subsection{Control Variables}

Informed by the environmental concern literature, we chose to include a number of control variables. Age impacts attitudes towards environmental issues, with younger individuals being more environmentally concerned than older ones (Kanagy et al., 1994; Franzen \& Meyer, 2010). The age of respondents in our sample ranged from 15 to 92 , with the average respondent being about 48 years old. We use a dummy variable to capture differences in the gender of the respondents (male $=1$; female $=0$ ). Women are in general more environmentally concerned than men (Xiao \& Dunlap, 2007; Hamilton et al., 2010), which is related to women's higher assessment of personal and family dangers (Hamilton et al., 2010; Davidson \& Freudenberg, 1996). Only $30 \%$ of the respondents were male due to the prevalence of the traditional breadwinner system (the husband was frequently out for work and the housewife was responding to the questionnaire). A dichotomous variable reflects respondent's race $(1=$ white, $0=$ blacks and other shades of color). The majority $(63 \%)$ of respondents self-identified as white. Studies show that environmental concern and behavior varies between certain ethnic groups with whites being more concerned than blacks (Nixon \& Saphores, 2009). Table 2 shows summary statistics for all variables included in the analysis. 
Table 2. Summary statistics of selected variables, displaying a group mean comparison (t-test) between Campinas metropolitan area (CMA) and Baixada Santista metropolitan area (BSMA)

\begin{tabular}{|c|c|c|c|c|c|c|c|}
\hline Variables & Mean & SD $^{\mathrm{a}}$ & Min & Max & BSMA & CMA & sig. ${ }^{b}$ \\
\hline \multicolumn{8}{|l|}{ Outcome } \\
\hline Env. concern scale & -0.02 & 0.66 & -6.05 & 0.29 & 0.04 & -0.07 & $* * *$ \\
\hline Global warming risk & 2.92 & 0.32 & 1.00 & 3.00 & 2.91 & 2.92 & \\
\hline Pollution for jobs & 0.95 & 0.23 & 0.00 & 1.00 & 0.95 & 0.94 & \\
\hline Control of natural resources & 0.92 & 0.26 & 0.00 & 1.00 & 0.97 & 0.88 & $* * *$ \\
\hline Nature is sacred & 0.95 & 0.22 & 0.00 & 1.00 & 0.97 & 0.93 & $* * *$ \\
\hline \multicolumn{8}{|l|}{ Predictors } \\
\hline CEC scale ${ }^{c}$ & 0.00 & 0.80 & -2.58 & 0.46 & -0.08 & 0.07 & $* * *$ \\
\hline Pavement condition & 3.48 & 0.98 & 1.00 & 4.00 & 3.39 & 3.57 & $* * *$ \\
\hline Curb/Gutter & 0.82 & 0.38 & 0.00 & 1.00 & 0.81 & 0.84 & \\
\hline Sidewalks & 0.83 & 0.37 & 0.00 & 1.00 & 0.81 & 0.85 & $* *$ \\
\hline Sewage collection & 3.69 & 0.79 & 1.00 & 4.00 & 3.57 & 3.79 & $* * *$ \\
\hline HEC scale ${ }^{c}$ & 0.01 & 0.67 & -2.92 & 1.79 & -0.15 & 0.14 & $* * *$ \\
\hline Problem: Contaminated areas & 2.76 & 0.70 & 1.00 & 4.00 & 2.54 & 2.94 & $* * *$ \\
\hline Problem: No nearby green spaces & 3.43 & 0.96 & 1.00 & 4.00 & 3.32 & 3.53 & $* * *$ \\
\hline Problem: Water supply \& drainage & 3.70 & 0.78 & 1.00 & 4.00 & 3.67 & 3.72 & \\
\hline Problem: Garbage collection & 3.85 & 0.57 & 1.00 & 4.00 & 3.79 & 3.90 & $* * *$ \\
\hline Problem: Insects \& rodents & 2.99 & 1.15 & 1.00 & 4.00 & 2.67 & 3.26 & $* * *$ \\
\hline Problem: Overgrown or denuded land & 3.33 & 1.02 & 1.00 & 4.00 & 3.25 & 3.40 & $* * *$ \\
\hline Low SES & 0.23 & 0.42 & 0.00 & 1.00 & 0.21 & 0.25 & $*$ \\
\hline Medium SES & 0.48 & 0.50 & 0.00 & 1.00 & 0.47 & 0.49 & \\
\hline High SES & 0.29 & 0.45 & 0.00 & 1.00 & 0.32 & 0.26 & $* * *$ \\
\hline \multicolumn{8}{|l|}{ Controls } \\
\hline Age & 47.96 & 16.77 & 15 & 92 & 47.82 & 48.08 & \\
\hline Gender (male) & 0.30 & 0.46 & 0.00 & 1.00 & 0.29 & 0.30 & \\
\hline Race (white) & 0.63 & 0.48 & 0.00 & 1.00 & 0.61 & 0.65 & $* *$ \\
\hline
\end{tabular}

Note: ${ }^{a}$ Standard deviation; ${ }^{b}$ Significance level for t-test comparing the sample mean for BSMA to the sample mean of $\mathrm{CMA} ;{ }^{\mathrm{c}} \mathrm{CEC}=$ Community environmental conditions, $\mathrm{HEC}=$ Household environmental conditions;

$*=\mathrm{p}<.05 ; * *=\mathrm{p}<.01 ; * * *=\mathrm{p}<.001$

Source: Data from Projeto Vulnerabilidade (NEPO/Unicamp).

\section{Estimation Strategy}

Our data shows a hierarchical structure in which individuals are nested within census tracts. To investigate whether SES (individual-level), household environmental conditions (individual-level), and community environmental conditions (census tract-level) serve as significant predictors of environmental concern, we employ multilevel regression models following Nawrotzki (2012). The multilevel models allow the average value of environmental concern (intercept) to vary across census tracts. In addition, we employ cross-level interactions to investigate whether the impact of environmental conditions on environmental concern differs by socio-economic status. Multilevel models have numerous statistical advantages over ordinary least square (OLS) regressions, because they adjust for clustering, different sample sizes for level-1 and level-2 units, heteroscedastic error terms, and varying numbers of cases within level-2 units (Luke, 2004). These models are 
especially well-suited for complex survey structures, such as the multi-stage sampling design used to collect our data.

Our modeling approach proceeded as follows: First, we estimated an unconditional or null model (Equation 1) to predict environmental concern (EC) for respondents $i$ nested in census tracts $j$ (148 census tracts for CMA; 114 census tracts for BSMA). In this model, the parameter $\beta_{0}$ represents the intercept or average value of environmental concern across the entire sample. However, the intercept is allowed to vary randomly across census tracts (level-2 units), and the random effect $u_{0 j}$ captures this variation. The parameter $r_{i j}$ is the conventional residual error term and accounts for unmeasured differences among individuals in environmental concern.

$$
E C_{i j}=\beta_{0}+u_{0 j}+r_{i j}
$$

The null model serves the purpose of computing the intraclass correlation coefficients (ICC) to measure the variance that occurs at the census tract-level. In our sample, 25\% (CMA) and 10\% (BSMA) of variation in environmental concern occurs at the census tract level. We then introduce our primary predictors and control variables into the model (Equation 2).

$$
E C_{i j}=\beta_{0}+\beta_{1}\left(\operatorname{cec}_{j}\right)+\beta_{2}\left(\text { hec }_{i j}\right)+\beta_{3}\left(\text { ses. } 2_{i j}\right)+\beta_{4}\left(\text { ses. }_{i j}\right)+\sum_{7}^{k} \beta_{k}\left(x_{i j}\right)+u_{0 j}+r_{i j}
$$

In this equation, $\beta_{1}$ represents the effect of community environmental conditions (cec) on environmental concern. The variable $c e c$ uses a subscript $j$, indicating that this measure varies only across census tracts. The parameters $\beta_{2}$ reflects the effect of household environmental conditions (hec). The parameters $\beta_{3}$ and $\beta_{4}$ show the effect of medium socioeconomic status (ses.2) and high socioeconomic status (ses.3), respectively, on environmental concern. These dummy variables use low socioeconomic status (ses.1) as reference category. The measures hec, ses.2, and ses.3, have an $i j$ subscript, indicating that these variables operate at the individual-level. The parameters, $\beta_{7}$ to $\beta_{k}$, demonstrate the effect of various individual-level control variables $\left(x_{i j}\right)$, which we represent using matrix notations to preserve space. In a final step of our modeling exercise, we include interactions (Equation 3).

$$
\begin{aligned}
E C_{i j}= & \beta_{0}+\beta_{1}\left(\operatorname{cec}_{j}\right)+\beta_{2}\left(\text { hec }_{i j}\right)+\beta_{3}\left(\text { ses. }_{2 i j}\right)+\beta_{4}\left(\text { ses. }_{i j}\right)+\beta_{5}\left(\text { hec }_{i j}{ }^{*} \text { ses. }_{i j}\right)+\beta_{6}\left(\text { hec }_{i j} * \text { ses. } 3_{i j}\right)+ \\
& \sum_{7}^{k} \beta_{k}\left(x_{i j}\right)+u_{0 j}+r_{i j}
\end{aligned}
$$

The significance and direction of parameters, $\beta_{5}$ and $\beta_{6}$, allows us to evaluate whether the effect of objective household environmental conditions on environmental concern differs between medium versus low SES, and high versus low SES, respectively. An additional model (Equation 4) investigates whether the effect of community environmental conditions ( $\mathrm{cec}$ ) varies by SES.

$$
\begin{aligned}
& E C_{i j}=\beta_{0}+\beta_{1}\left(\operatorname{cec}_{j}\right)+\beta_{2}\left(h e c_{i j}\right)+\beta_{3}\left(\operatorname{ses} .2_{i j}\right)+\beta_{4}\left(\operatorname{ses} .3_{i j}\right)+\beta_{5}\left(\operatorname{cec}_{j} * \operatorname{ses} .2_{i j}\right)+\beta_{6}\left(\operatorname{cec}_{j} * \operatorname{ses} .3_{i j}\right)+ \\
& \sum_{7}^{k} \beta_{k}\left(x_{i j}\right)+u_{0 j}+u_{1 j}\left(\text { ses. } 2_{i j}\right)+u_{2 j}\left(\text { ses. } 3_{i j}\right)+r_{i j}
\end{aligned}
$$

This interaction involves two variables that operate at different levels $($ cec $=$ level-2, ses $=$ level-1) and is therefore referred to as cross-level interaction. We follow a conventional approach in multilevel modeling and allow the slope of the level-1 variable, involved in the cross-level interaction, to vary randomly across level-2 units (Subramanian et al., 2009; Dedrick et al., 2009). In Equation 4, the coefficients $u_{1 j}$ and $u_{2 j}$ represent the random slope parameters for ses. 2 and ses.3, respectively. Using the lme4 package (Bates, 2010) within the "R" statistical environment version 3.0.1 (R Core Team, 2013), we fit the multilevel models.

\section{Results and Discussion}

We began our quest with the intent to explore the relation between environmental concern, SES, and "objective" environmental conditions by using a simple t-test to compare the difference of mean values between CMA and BSMA (see Table 2). The results indicate that the two metropolitan areas differ significantly in their environmental concern; BSMA residents are more environmentally concerned than residents of CMA. The more environmentally concerned BSMA residents have, on average, higher levels of SES, lending descriptive evidence to the affluence hypothesis (Franzen \& Meyer, 2010). Concurrently, however, those more environmentally concerned BSMA residents tend to reside in areas with worse "objective" environmental conditions (c.f., Rohrschneider, 1990), providing initial support for the objective problems hypothesis. Regional differences in social perceptions, local histories, and environmental realities, as well as unique cultural and structural features of the particular urban region may account for some of these variations (Cunha, 2006; Crespo, 
2003). Because of these differences, we chose to conduct separate analyses for each metropolitan area. Table 3 displays the results of additive multilevel models for the investigation on determinants of environmental concern in CMA and BSMA, respectively.

Table 3. Additive random intercept models, predicting environmental concern (Env. concern scale) for Campinas metropolitan area (CMA) and Baixada Santista metropolitan area (BSMA) as function of environmental conditions and SES

\begin{tabular}{|c|c|c|c|c|c|c|}
\hline & \multicolumn{2}{|c|}{ Model 1} & \multicolumn{2}{|c|}{ Model 2} & \multicolumn{2}{|c|}{ Model 3} \\
\hline & b & sig. & b & sig. & b & sig. \\
\hline \multicolumn{7}{|l|}{ Panel A: CMA } \\
\hline Intercept & -0.07 & * & -0.15 & $* * *$ & -0.17 & $*$ \\
\hline CEC & & & -0.09 & $*$ & -0.10 & $*$ \\
\hline HEC & & & 0.02 & & 0.02 & \\
\hline Medium SES & & & 0.09 & $*$ & 0.09 & $*$ \\
\hline High SES & & & 0.14 & $* *$ & 0.14 & $* *$ \\
\hline Age & & & & & 0.00 & \\
\hline Gender (male) & & & & & -0.02 & \\
\hline Race (white) & & & & & 0.03 & \\
\hline \multicolumn{7}{|l|}{ Model statistics } \\
\hline Residual variance & 0.324 & & 0.323 & & 0.323 & \\
\hline Variance Intercept & 0.106 & & 0.105 & & 0.105 & \\
\hline $\mathrm{BIC}$ & 3337 & & 3374 & & 3417 & \\
\hline $\mathrm{N}$ & 1801 & & 1801 & & 1801 & \\
\hline \multicolumn{7}{|l|}{ Panel B: BSMA } \\
\hline Intercept & 0.04 & & -0.06 & & 0.00 & \\
\hline CEC & & & 0.03 & & 0.03 & \\
\hline HEC & & & -0.07 & $*$ & -0.07 & $*$ \\
\hline Medium SES & & & 0.08 & & 0.07 & \\
\hline High SES & & & 0.18 & $* * *$ & 0.17 & $* *$ \\
\hline Age & & & & & 0.00 & \\
\hline Gender (male) & & & & & -0.05 & \\
\hline Race (white) & & & & & 0.02 & \\
\hline \multicolumn{7}{|l|}{ Model statistics } \\
\hline Residual variance & 0.384 & & 0.380 & & 0.380 & \\
\hline Variance Intercept & 0.043 & & 0.044 & & 0.044 & \\
\hline $\mathrm{BIC}$ & 3083 & & 3114 & & 3154 & \\
\hline $\mathrm{N}$ & 1569 & & 1569 & & 1569 & \\
\hline
\end{tabular}

Note: Low SES was used as reference category for the Medium SES and High SES dummy variables. CEC = Community environmental conditions, HEC $=$ Household environmental conditions. We used the variance inflation factor (VIF) statistics to test for multicollinearity. For both metropolitan areas VIF remains below a value of two, confirming that mutlicollinearity is of no concern in our analysis.

$*=\mathrm{p}<.05 ; * *=\mathrm{p}<.01 ; * * *=\mathrm{p}<.001 ;$

Source: Data from Projeto Vulnerabilidade (NEPO/Unicamp). 
Even though mostly not significant, the control variables behave as anticipated from our literature review. For both metropolitan areas, the most environmentally concerned respondents can be characterized as white females (Nixon \& Saphores, 2009; Xiao \& Dunlap, 2007). Non-significant results of these control measures are not uncommon in the published environmental concern literature (see Nawrotzki, 2012, Table 3).

However, the measures of primary concern for this analysis demonstrate some significant effects. A significant and positive effect of SES for both metropolitan areas allows us to address our first research question: Are affluent households more concerned about the environment than low SES households in metropolitan Brazil? In line with prior work (Meyer \& Liebe, 2010; Franzen \& Meyer, 2010; Guedes et al., 2012; Nawrotzki, 2012) we observe that the affluent are more environmentally concerned in metropolitan Brazil. In CMA, for example, medium SES individuals are 0.09 units more environmentally concerned than low SES individuals $(\mathrm{p}<.05)$. This difference increases to 0.14 units, comparing high SES individuals to low SES individuals $(\mathrm{p}<.01)$. These results lend strong support to the affluence (Diekmann \& Franzen, 1999) and post-materialist (Inglehart, 1990) hypotheses. The single-item analysis (Table 4) demonstrates that the positive effect of SES on environmental concern emerges mainly for the "global warming risk" and "pollution for jobs" items.

Table 4. Additive random intercept models estimated for individual environmental concern items for Campinas metropolitan area (CMA) and Baixada Santista metropolitan area (BSMA)

\begin{tabular}{|c|c|c|c|c|c|c|c|c|}
\hline & \multicolumn{2}{|c|}{$\begin{array}{c}\text { Global warming } \\
\text { risk }\end{array}$} & \multicolumn{2}{|c|}{$\begin{array}{c}\text { Pollution for } \\
\text { jobs }\end{array}$} & \multicolumn{2}{|c|}{$\begin{array}{c}\text { Control over natural } \\
\text { resources }\end{array}$} & \multicolumn{2}{|c|}{$\begin{array}{l}\text { Nature is } \\
\text { sacred }\end{array}$} \\
\hline & b & sig. & b & sig. & b & sig. & b & sig. \\
\hline \multicolumn{9}{|l|}{ Panel A: CMA } \\
\hline CEC & -0.01 & & -0.11 & & -0.87 & & -0.59 & $*$ \\
\hline HEC & 0.02 & & 0.20 & & 0.07 & & 0.01 & \\
\hline Medium SES & 0.08 & $* * *$ & -0.11 & & 0.21 & & 0.18 & \\
\hline High SES & 0.11 & $* * *$ & -0.04 & & 0.39 & & 0.16 & \\
\hline \multicolumn{9}{|l|}{ Panel B: BSMA } \\
\hline CEC & 0.02 & & -0.12 & & -0.24 & & -0.44 & \\
\hline HEC & -0.03 & & -0.05 & & 0.21 & & -0.14 & \\
\hline Medium SES & 0.00 & & 0.80 & $* *$ & 0.21 & & 0.33 & \\
\hline High SES & 0.07 & $*$ & 1.20 & $* *$ & 0.59 & & 0.42 & \\
\hline
\end{tabular}

Note: $\mathrm{CEC}=$ Community environmental conditions, $\mathrm{HEC}=$ Household environmental conditions. Each model employs a different outcome variable as indicated by the respective column heading. All models control for age gender and race (not displayed to preserve space). We encountered convergence issues for the "Nature is sacred" model for BSMA, due to the large number of respondents $(97 \%)$ considering nature to be sacred. Thus, the coefficients for this model should be evaluated with caution. Due to the dichotomous nature of the respective outcome variables, Models 2-4 (pollution for jobs, control over natural resources, nature is sacred) were estimated using a logit link function.

$*=\mathrm{p}<.05 ; * *=\mathrm{p}<.01 ; * * *=\mathrm{p}<.001$

Source: Data from Projeto Vulnerabilidade (NEPO/Unicamp).

Addressing our second research question (Do "objective" environmental conditions in metropolitan Brazil impact environmental concern?), we find a significant impact of locally specific environmental conditions on environmental concern, in line with Brechin (1999) and Whittaker, Segura, and Bowler (2005) (see Table 3). However, this relationship differs for the two metropolitan areas. For CMA, a negative association between community environmental conditions and environmental concern exists $(b=-0.10, p<.05)$. Individuals are most environmentally concerned when living in neighborhoods of poor local infrastructure. As such, our findings seem to support Abramson (1997) and the objective problems portion of Inglehart's (1995) OPSV hypothesis. On the other hand, the environmental conditions in the immediate surroundings of a house do no impact environmental concern for residents of CMA. 
In contrast, for BSMA, household environmental conditions matter $(b=-0.07, p<.01)$, whereas community environmental conditions do not effect environmental concern. However, the direction (negative sign) of the significant effect in BSMA is similar to that observed in CMA. Environmental concern is highest among individuals experiencing poor local household environmental conditions. Other authors (Hunter, Strife, \& Twine, 2010) also observed spatial variations in the relationship between objective problems and environmental concern, which likely result from different histories of urban development and variation in local biophysical characteristics (c.f., Pasternak, 2006; Torres, Alves, \& Oliveira, 2007). Although the sign of the effects is similarly negative, the objective environmental condition measures are largely insignificant in the single-item analysis (see Table 4).

To answer our third research question (Is the relation between objective environmental conditions and environmental concern in metropolitan Brazil different for individuals of varying socioeconomic background?), we introduce interaction terms in the models (see Table 5).

Table 5. Interaction models, investigating the relationship between SES and environmental conditions in predicting environmental concern (Env. concern scale) for Campinas metropolitan area (CMA) and Baixada Santista metropolitan area (BSMA)

\begin{tabular}{lcccc}
\hline & \multicolumn{2}{c}{ Model 1 } & \multicolumn{2}{c}{ Model 2 } \\
& b & sig. & b & sig. \\
\hline Panel A: CMA & & & & \\
CEC & -0.11 & & -0.10 & $*$ \\
HEC & 0.02 & & -0.05 & \\
Medium SES & 0.09 & $*$ & 0.09 & $* *$ \\
High SES & 0.14 & $*$ & 0.15 & $* *$ \\
CEC x Medium SES & 0.02 & & & \\
CEC x High SES & 0.03 & & & \\
HEC x Medium SES & & & 0.11 & \\
HEC x High SES & & & 0.07 & \\
Panel B: BSMA & & & & \\
CEC & 0.02 & & 0.04 & \\
HEC & -0.05 & & -0.17 & $* * *$ \\
Medium SES & 0.06 & & 0.10 & $*$ \\
High SES & 0.03 & & 0.16 & $* *$ \\
CEC x Medium SES & 0.00 & & & \\
CEC x High SES & 0.34 & $* *$ & & \\
HEC x Medium SES & & & 0.10 & \\
HEC x High SES & & & 0.25 & $* * *$ \\
\hline
\end{tabular}

Note: Low SES was used as reference category for the Medium SES and High SES dummy variables. CEC $=$ Community environmental conditions, HEC $=$ Household environmental conditions. All models control for age gender and race (not displayed to preserve space); To provide a meaningful interpretation of the coefficients involved in the cross-level interaction, a different parameterization was used and all variables (except for the SES dummy variables) were grand mean centered.

$*=\mathrm{p}<.05 ; * *=\mathrm{p}<.01 ; * * *=\mathrm{p}<.001$

Source: Data from Projeto Vulnerabilidade (NEPO/Unicamp). 
Table 5 shows no significant interaction for CMA. Thus, in this area the association between community environmental conditions and environmental concern is independent of SES. However, we found a significant interactions between community $(b=0.34, p<.01)$, as well as household $(b=0.25, p<.001)$ environmental conditions, and SES among residents of BSMA. Graphical visualizations help to explain these relationships.
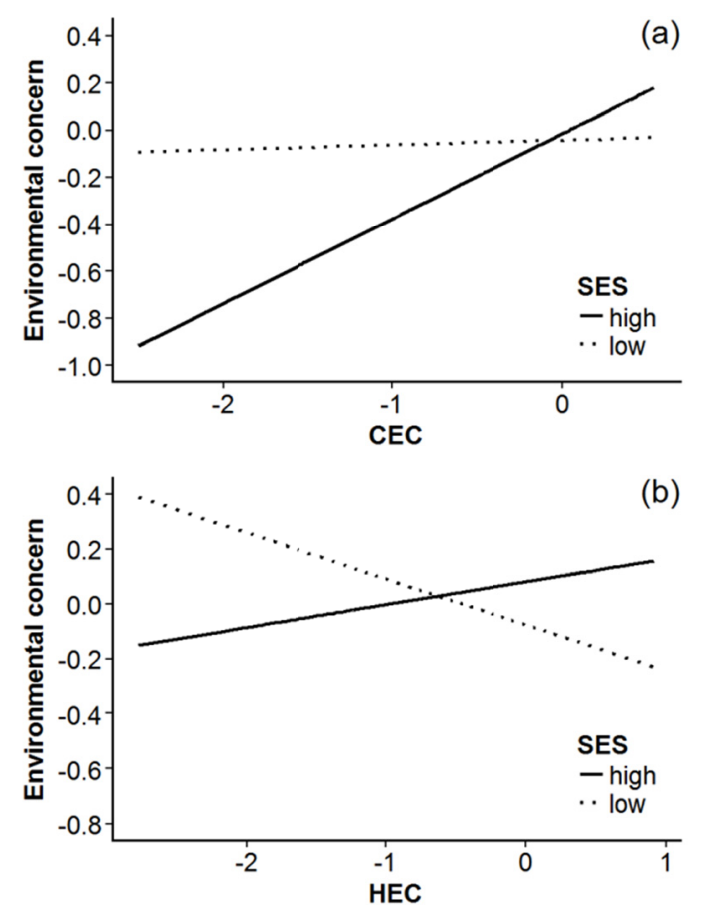

Figure 2. Visualization of the interaction between SES and objective environmental conditions, predicting environmental concern for Baixada Santista metropolitan area (BSMA)

Note: Panel (a) shows the interaction between community environmental conditions (CEC) and SES while panel (b) shows the interaction between household environmental conditions (HEC) and SES. The community and household environmental conditions scales were grand mean centered. The plots are based on predicted values and were generated using the R package ggplot2 (Wickham, 2009).

Figure 2, panel (a) shows that for low SES individuals, a decline in community environmental conditions does not lead to changes in environmental concern. However, among high SES individuals, lower environmental conditions are associated with lower levels of environmental concern. Panel (b) shows a similar picture; poorer environmental conditions correlate with lower levels of environmental concern for the most affluent households. However, for low SES residents, a decline in local environmental conditions relates to an increase in environmental concern. The single-item analysis (Table 6) confirms that interactions between SES and objective environmental conditions mainly occur for BSMA. The single-item models further reveal that this interaction emerges for residents' opinion regarding the tradeoff between job generation and pollution and to a lesser degree on the topic of global warming risk. 
Table 6. Random slope, interaction models, investigating the relationship between SES and objective environmental conditions for individual environmental concern items for Campinas metropolitan area (CMA) and Baixada Santista metropolitan area (BSMA)

\begin{tabular}{|c|c|c|c|c|c|c|c|c|}
\hline & \multicolumn{2}{|c|}{ Global warming risk } & \multicolumn{2}{|c|}{ Pollution for jobs } & \multicolumn{2}{|c|}{$\begin{array}{c}\text { Control over } \\
\text { natural resources }\end{array}$} & \multicolumn{2}{|c|}{$\begin{array}{l}\text { Nature is } \\
\text { sacred }\end{array}$} \\
\hline & b & sig. & b & sig. & $\mathbf{b}$ & sig. & b & sig. \\
\hline \multicolumn{9}{|c|}{ Panel A: CMA - Community environmental conditions } \\
\hline CEC & -0.03 & & -0.01 & & -0.04 & & -0.02 & \\
\hline HEC & 0.02 & & 0.01 & & 0.01 & & 0.00 & \\
\hline Medium SES & 0.09 & $* * *$ & 0.00 & & 0.01 & & 0.00 & \\
\hline High SES & 0.13 & $* * *$ & 0.01 & & 0.00 & & 0.01 & \\
\hline CEC x Medium SES & 0.03 & & 0.02 & & -0.01 & & -0.02 & \\
\hline CEC $x$ High SES & -0.01 & & -0.02 & & 0.08 & & -0.04 & \\
\hline \multicolumn{9}{|c|}{ Panel B: CMA - Household environmental conditions } \\
\hline $\mathrm{CEC}$ & -0.01 & & -0.12 & & -0.86 & & -0.59 & * \\
\hline HEC & -0.02 & & -0.59 & & 0.21 & & 0.00 & \\
\hline Medium SES & 0.09 & $* * *$ & -0.03 & & 0.18 & & 0.18 & \\
\hline High SES & 0.11 & $* * *$ & 0.06 & & 0.36 & & 0.18 & \\
\hline HEC $x$ Medium SES & 0.05 & & 1.21 & $*$ & -0.25 & & 0.10 & \\
\hline HEC $x$ High SES & 0.06 & & 0.55 & & -0.10 & & -0.10 & \\
\hline \multicolumn{9}{|c|}{ Panel C: BSMA - Community environmental conditions } \\
\hline CEC & 0.04 & & -0.03 & & 0.00 & & -0.02 & \\
\hline HEC & -0.03 & & 0.00 & & 0.01 & & 0.00 & \\
\hline Medium SES & -0.02 & & 0.06 & $*$ & 0.00 & & 0.01 & \\
\hline High SES & -0.02 & & 0.03 & & 0.00 & & 0.01 & \\
\hline CEC x Medium SES & -0.03 & & 0.02 & & 0.00 & & 0.01 & \\
\hline CEC $x$ High SES & 0.13 & * & 0.14 & $* *$ & 0.02 & & 0.02 & \\
\hline \multicolumn{9}{|c|}{ Panel D: BSMA - Household environmental conditions } \\
\hline CEC & 0.03 & & -0.02 & & -0.14 & & -0.24 & \\
\hline HEC & -0.02 & & -0.87 & $*$ & -0.23 & & -1.14 & \\
\hline Medium SES & 0.00 & & 0.83 & $* *$ & 0.23 & & 0.28 & \\
\hline High SES & 0.06 & & 1.22 & $* *$ & 0.65 & & 0.06 & \\
\hline HEC x Medium SES & -0.01 & & 0.65 & & 0.11 & & 0.80 & \\
\hline HEC x High SES & 0.00 & & 2.14 & $* * *$ & 1.23 & & 1.87 & \\
\hline
\end{tabular}

Note: $\mathrm{CEC}=$ Community environmental conditions; HEC $=$ Household environmental conditions. Each model employs a different outcome variable as indicated by the respective column heading. All models control for age gender and race (not displayed to preserve space). Due to the dichotomous nature of the respective outcome variables, Models 2-4 (pollution for jobs, control over natural resources, nature is sacred) were estimated using a logit link function.

$*=\mathrm{p}<.05 ; * *=\mathrm{p}<.01 ; * * *=\mathrm{p}<.001$

Source: Data from Projeto Vulnerabilidade (NEPO/Unicamp).

The findings from the interaction models largely support Inglehart's (1995) OPSV hypothesis for urban areas in Brazil. A worsening in local environmental conditions corresponds with an increase in environmental concern 
for low SES-groups (our individual-level analog for less developed countries), but not for high SES groups (our individual-level analog for industrialized countries). Selected residential mobility helps to explain the positive association between environmental concern and environmental conditions for the most affluent individuals. The affluent have the financial means to choose their residence according to their preferences and levels of concern, a freedom that the poor usually do not have (Crowder \& Downey, 2010). Those affluent individuals who are truly concerned with the environment chose to live in pleasant areas with better environmental conditions, while other affluent residents who do not care about the environment prefer to live in areas of reduced environmental quality and cheaper rental costs.

\section{Conclusion and Policy Recommendations}

\subsection{Summary}

The present analysis acts as an initial step towards understanding the complex relationship between wealth, objective environmental conditions, and environmental concern in urban Brazil. The results allow for three conclusions: First, the post-materialist (Inglehart, 1990) and affluence hypothesis (Franzen \& Meyer, 2010) better predict the positive relationship between environmental concern and wealth in the metropolitan areas of Baixada Santista and Campinas, compared to the global environmentalism hypothesis (Dunlap \& York, 2008).

Second, "objective" environmental conditions are significantly associated with environmental concern in urban Brazil. Individuals residing in areas with poor environmental conditions tend to be more environmentally concerned (Abramson, 1997). However, we find some region-specific variation in this association, which falls in line with prior work, stressing the importance of space on environmental concern (Chen et al., 2011; Hamilton et al., 2010; Brodi et al., 2004). While community environmental conditions matter in CMA, household environmental conditions are more important in BSMA.

Third, our analysis reveals a non-linear relationship between environmental conditions and SES in predicting environmental concern, supporting Inglehart's (1995) nation-level OPSV hypothesis at the individual level. Among poor households, an increase in environmental concern corresponds to the deterioration in household environmental conditions. In contrast, among the wealthy, residential mobility helps to explain why the most environmentally concerned live in locations with the best environmental conditions. However, this non-linear relationship only emerges for BMSA residents.

\subsection{Limitations}

Although carefully conducted, this study is not without limitations. Similar to most surveys on environmental concern, our "objective" environmental conditions measures contain a certain level of subjectivity, because they involve the evaluation of the respondents. As such, future studies might employ more objective measures of environmental quality based on the assessment of independent experts, or by employing satellite-based data on environmental conditions (e.g., Gutierrez, 2010). More detailed information on sewage treatment and air pollution would be particularly useful. In addition, some of the environmental conditions measures are ambiguously worded and need to be improved in future data collection efforts. For example, we will consider including separate items distinguishing issues of water supply from problems with drainage systems. However, the employed variables to represent household and community environmental conditions were derived from the Brazilian Demographic Census (IBGE, 2013). Although not without limitations, we chose to use the same items to allow for the comparison between our survey results and those obtained by the Brazilian Demographic Census.

We also acknowledge the potential bias in the level of environmental concern in our study areas. As previously mentioned, respondents demonstrated high levels of environmental concern. Our study took place in the most developed and urbanized region of Brazil, and thus, our findings might not apply to less developed urban or rural areas. Although, we borrowed the environmental concern questions from previous questionnaires applied nationally by the Brazilian Ministry of the Environment (Crespo, 2003), some of these items might need improvement. For example, three of the four environmental concern variables limit answer options to agree/disagree responses, which might have led to somewhat biased responses. Future research might consider employing Likert scales for all environmental concern items to improve the sensitivity of those measures. However, in its fifth edition, the nationally representative survey "O que os Brasileiros Pensam do Meio-Ambiente e do Consumo Sustentável" (What Brazilians Think of the Environment and Sustainable Consumption), conducted by the Brazilian Ministry of the Environment, changed the binary environmental concern questions to four-points Likert scales. Results suggest that most of the questions on environmental concern are answered using the extreme categories (MMA, 2012). As such, a wider answer option range (e.g., 5 
or 7 points Likert scale), and perhaps rewording of the questions might be necessary to obtain higher variations in the responses.

Finally, the present analysis and conclusions rely entirely on quantitative data and lack contextual embeddedness Qualitative data collected through in-depth interviews would be useful to explore why certain groups of residents perceive particular objective environmental problems as serious, and how historic context and geographical differences impact the development of environmental concern.

\subsection{Policy Implications}

We observe that among the poor, an increase in environmental concern links to a decline in local (household) environmental conditions. However, concern about the environment does not necessary translate into action. Although poor households in metropolitan Brazil engage in pro-environmental public behavior, such as protests against polluting companies (Guedes \& Carmo, 2012), these households may lack the resources (e.g., money, time, knowledge) to change their local and community environments. Thus, publically funded programs should build on the available environmental concern and empower low SES households to improve the environmental conditions of their neighborhoods and community by making repairs and construction materials available at reduced prices and by community mobilization through "community action days".

\section{Acknowledgments}

We gratefully acknowledge that FAPESP (Fundo de Amparo e Pesquisa de Estado de São Paulo) and CNPq (National Counsel of Technological and Scientific Development) research agencies funded the collection and processing of data used in this study. We thank José Marcos Pinto da Cunha for making the data available. Special thanks to the journal editor and anonymous reviewers for insightful comments and suggestions on earlier drafts of this manuscript. We express our thanks to Jamie Jones for her careful editing and helpful suggestions. Publication of this article was funded by the University of Colorado Boulder Libraries Open Access Fund.

\section{References}

ABEP. (2008). Critério de Classificação Econômica Brasil. São Paulo, Brazil: Associação brasileira de empresas de pesquisa.

Abramson, P. R. (1997). Postmaterialism and environmentalism: A comment on an analysis and a reappraisal. Social Science Quarterly, 78(1), 21-23.

Abramson, P. R., \& Inglehart, R. (1995). Value change in global perspective. Ann Arbor, MI: University of Michigan Press.

Adeola, F. O. (2004). Environmentalism and risk perception: Empirical analysis of black and white differentials and convergence. Society \& Natural Resources, 17(10), 911-939. http://dx.doi.org/10.1080/08941920490505329

Bates, D. M. (2010). lme4: Mixed-effects modeling with R. New York: Springer.

Bayard, B., \& Jolly, C. (2007). Environmental behavior structure and socio-economic conditions of hillside farmers: A multiple-group structural equation modeling approach. Ecological Economics, 62(3-4), 433-440. http://dx.doi.org/10.1016/j.ecolecon.2006.07.004

Bechtel, R. B., Verdugo, V. C., \& Pinheiro, J. D. Q. (1999). Environmental belief systems - United States, Brazil, $\begin{array}{llll}\text { and Mexico. Journal of Cross-Cultural Psychology, 30(1), 122-128. } & \text {. }\end{array}$ http://dx.doi.org/10.1177/0022022199030001008

Bollen, K. A. (1989). Measurement models: The relation between latent and observed variables. In K. A. Bollen (Ed.), Structural equations with latent variables (pp. 179-225). New York: John Wiley \& Sons.

Brechin, S. R. (1999). Objective problems, subjective values, and global environmentalism: Evaluating the postmaterialist argument and challenging a new explanation. Social Science Quarterly, 80(4), 793-809.

Brechin, S. R., \& Kempton, W. (1994). Global environmentalism: A challenge to the postmaterialism thesis. Social Science Quarterly, 75(2), 245-269.

Brody, S. D., Highfield, W., \& Alston, L. (2004). Does location matter? Measuring environmental perceptions of creeks in two San Antonio watersheds. Environment and Behavior, 36(2), 229-250. http://dx.doi.org/10.1177/0013916503256900 
Brulle, R. J., \& Pellow, D. N. (2006). Environmental justice: Human health and environmental inequalities. Annual Review of Public Health, 27, 103-124. $\mathrm{http}: / / \mathrm{dx}$.doi.org/10.1146/annurev.publhealth.27.021405.102124

Cattell, R. B., \& Kline, P. (1977). The scientific analysis of personality and motivation. London: Academic Press.

Chen, X., Peterson, M. N., Hull, V., Lu, C., Lee, G. D., Hong, D., \& Liu, J. (2011). Effects of attitudinal and sociodemographic factors on pro-environmental behaviour in urban China. Environmental Conservation, 38(1), 45-52. http://dx.doi.org/10.1017/S037689291000086X

Cortina, J. M. (1993). What is coefficient alpha? An examination of theory and applications. Journal of Applied Psychology, 78(1), 98-104. http://dx.doi.org/10.1037/0021-9010.78.1.98

Crespo, S. (2003). Uma visão sobre a evolução da consciência ambiental no Brasil nos anos 1990. In A. Trigueiro (Ed.), Meio Ambiente no Século 21: 21 especialistas falam da questão ambiental nas suas áreas de conhecimento. Rio de Janeiro, Brazil: Sextante.

Cronbach, L. J. (1951). Coefficient alpha and the internal structure of tests. Psychometrika, 16(3), 297-334. http://dx.doi.org/10.1007/BF02310555

Crowder, K., \& Downey, L. (2010). Interneighborhood Migration, Race, and Environmental Hazards: Modeling Microlevel Processes of Environmental Inequality. American Journal of Sociology, 115(4), 1110-1149. http://dx.doi.org/10.1086/649576

Cunha, J. M. P., Jakob, A. A. E., Hogan, D. J., \& Carmo, R. L. (2006). A vulnerabilidade social no contexto metropolitano: o caso de Campinas. In J. M. P. Cunha (Ed.), Novas metrópoles paulistas: população, vulnerabilidade e segregação (pp. 143-168). Campinas, Brazil: NEPO/UNICAMP.

Davidson, D. J., \& Freudenburg, W. R. (1996). Gender and environmental risk concerns: A review and analysis of

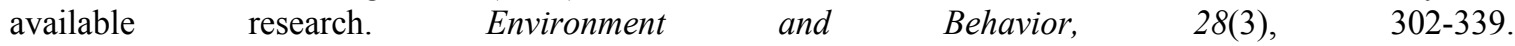
http://dx.doi.org/10.1177/0013916596283003

Dedrick, R. F., Ferron, J. M., Hess, M. R., Hogarty, K. Y., Kromrey, J. D., Lang, T. R., ... Lee, R. S. (2009). Multilevel Modeling: A Review of Methodological Issues and Applications. Review of Educational Research, 79(1), 69-102. http://dx.doi.org/10.3102/0034654308325581

Diekmann, A., \& Franzen, A. (1999). The wealth of nations and environmental concern. Environment and Behavior, 31(4), 540-549. http://dx.doi.org/10.1177/00139169921972227

Drori, I., \& Yuchtman-Yaar, E. (2002). Environmental vulnerability in public perceptions and attitudes: The case of Israel's urban centers. Social Science Quarterly, 83(1), 53-63. http://dx.doi.org/10.1111/1540-6237.00070

Drost, E. A. (2011). Validity and reliability in social science research. Education Research and Perspectives, 38(1), 105-123.

Dunlap, R. E., \& Mertig, A. G. (1997). Global environmental concern: An anomaly for postmaterialism. Social Science Quarterly, 78(1), 24-29.

Dunlap, R. E., \& Yolk, R. (2008). The globalization of environmental concern and the limits of the postmaterialist values explanation: Evidence from four multinational surveys. Sociological Quarterly, 49(3), 529-563. http://dx.doi.org/10.1111/j.1533-8525.2008.00127.x

ECLAC. (2009). Climate change and development in Latin America and the Caribbean. Overview 2009. In J. Samaniego (Ed.). Washington, D.C.: United Nations, Economic Commission for Latin America and the Caribbean.

Frank, D. J. (1997). Science, nature, and the globalization of the environment, 1870-1990. Social Forces, 76(2), 409-435.

Frank, D. J., Hironaka, A., Meyer, J. W., Schofer, E., \& Brandon Tuma, N. (1999). The Rationalization and organization of nature in world culture. In J. Boli \& G. M. Thomas (Eds.), Constructing World culture: International Nongovernmental Organizations Since 1875 (pp. 81-99). Stanford, CA: Stanford University Press.

Franzen, A. (2003). Environmental attitudes in international comparison: An analysis of the ISSP surveys 1993 and 2000. Social Science Quarterly, 84(2), 297-308. http://dx.doi.org/10.1111/1540-6237.8402005 
Franzen, A., \& Meyer, R. (2010). Environmental Attitudes in Cross-National Perspective: A Multilevel Analysis of the ISSP 1993 and 2000. European Sociological Review, 26(2), 219-234. http://dx.doi.org/10.1093/esr/jcp018

Gelissen, J. (2007). Explaining popular support for environmental protection - A multilevel analysis of 50 nations. Environment and Behavior, 39(3), 392-415. http://dx.doi.org/10.1177/0013916506292014

Grineski, S. E., Collins, T. W., Aguilar, M. D. R., \& Aldouri, R. (2010). No Safe Place: Environmental Hazards \& Injustice along Mexico's Northern Border. Social Forces, 88(5), 2241-2265. http://dx.doi.org/10.1353/sof.2010.0036

Guedes, G. R., \& Carmo, R. L. (2012). Socioeconomic and residential differences in environmental perception and behavior: Insights from metropolitan Brazil. In L. Turunen \& A. Koskinen (Eds.), Urbanization and the global environment (pp. 109-138). New York: Nova Publishers.

Guedes, G. R., Hora, A. M., Dias, C. A., Braga, E. O., \& Soares, M. M. (2012). Critical evaluation of the New Environmental Paradigm scale in low developing settings. In G. R. Guedes \& R. Ojima (Eds.), Territory, population mobility, and the environment (pp. 369-394). Governador Valadares, Brazil: Vale do Rio Doce University Press.

Guha, R., \& Martinez-Alier, J. (1997). Varieties of environmentalism: Essays North and South. London: Earthscan.

Gutierrez, E. (2010). Using satellite imagery to measure the relationship between air quality and infant mortality: An empirical study for Mexico. Population and Environment, 31(4), 203-222. http://dx.doi.org/10.1007/s11111-009-0096-y

Gwatkin, D. R., Rutstein, S., Johnson, K., Suliman, E., Wagstaff, A., \& Amouzou, A. (2007). Socio-economic differences in health, nutrition, and population within developing countries: An overview. Health Nutrition and Population. Washington, D.C.: The World Bank.

Hamilton, L. C., Colocousis, C. R., \& Duncan, C. M. (2010). Place Effects on Environmental Views. Rural Sociology, 75(2), 326-347. http://dx.doi.org/10.1111/j.1549-0831.2010.00013.x

Hinkin, T. R. (1995). A review of scale development practices in the study of organizations. Journal of Management, 21(5), 967-988. http://dx.doi.org/10.1177/014920639502100509

Hunter, L. M., Strife, S., \& Twine, W. (2010). Environmental Perceptions of Rural South African Residents: The Complex Nature of Environmental Concern. Society \& Natural Resources, 23(6), 525-541. http://dx.doi.org/10.1080/08941920903357782

IBGE. (2013). Demographic Talley - 2007. Rio de Janeiro, Brazil: Instituto Brasileiro de Geografia e Estatistica $\begin{array}{lllll}\text { (IBGE). } & \text { Retrieved July } & 14 & & \text { from }\end{array}$ http://www.sidra.ibge.gov.br/bda/tabela/protabl.asp? $\mathrm{c}=794 \& \mathrm{z}=\mathrm{cd} \& \mathrm{o}=35 \& \mathrm{i}=\mathrm{P}$

Inglehart, R. (1990). Culture shift in advanced industrial society. Princeton, N.J.: Princeton University Press.

Inglehart, R. (1995). Public support for environmental-protection: Objective problems and subjective values in 43 societies. Ps-Political Science \& Politics, 28(1), 57-72.

Inglehart, R., \& Baker, W. E. (2000). Modernization, cultural change, and the persistence of traditional values. American Sociological Review, 65(1), 19-51. http://dx.doi.org/10.2307/2657288

IPCC. (2007). The Physical Science Basis. Contribution of Working Group I to the Fourth Assessment Report of the Intergovernmental Panel on Climate Change. In S. Solomon, D. Qin, M. Manning, Z. Chen, M. Marquis, K. B. Averyt, M. Tignor, \& H. L. Miller (Eds.), Climate Change 2007 (pp. 996). Cambridge, United Kingdom, New York, NY.

Jessup, B. (2010). Plural and hybrid environmental values a discourse analysis of the wind energy conflict in Australia and the United Kingdom. Environmental Politics, 19(1), 21-44. http://dx.doi.org/10.1080/09644010903396069

Kahn, M. E. (2002). Demographic change and the demand for environmental regulation. Journal of Policy Analysis and Management, 21(1), 45-62. http://dx.doi.org/10.1002/pam.1039

Kanagy, C. L., Humphrey, C. R., \& Firebaugh, G. (1994). Surging environmentalism: Changing public-opinion or changing publics. Social Science Quarterly, 75(4), 804-819. 
Kemmelmeier, M., Krol, G., \& Kim, Y. H. (2002). Values, economics, and proenvironmental attitudes in 22 societies. Cross-Cultural Research, 36(3), 256-285. http://dx.doi.org/10.1177/10697102036003004

Kidd, Q., \& Lee, A.-R. (1997). Postmaterialist values and the environment: A critique and reappraisal. Social Science Quarterly, 78(1), 1-15.

Kline, P. (2000). The handbook of psychological testing (2nd ed.). London: Routledge.

Lance, C. E., Butts, M. M., \& Michels, L. C. (2006). The sources of four commonly reported cutoff criteria - What did they really say? Organizational Research Methods, 9(2), 202-220. http://dx.doi.org/10.1177/1094428105284919

Luke, D. A. (2004). Multilevel modeling. Sage university papers series: Qunatitative applications in the social sciences 143. Thousand Oaks, CA: Sage Publications, Inc.

Marquart-Pyatt, S. T. (2008). Are there similar sources of environmental concern? Comparing industrialized countries. Social Science Quarterly, 89(5), 1312-1335. http://dx.doi.org/10.1111/j.1540-6237.2008.00567.x

Mberu, B. U. (2006). Internal migration and household living conditions in Ethiopia. Demographic Research, 14, 509-539.

Meyer, R., \& Liebe, U. (2010). Are the affluent prepared to pay for the planet? Explaining willingness to pay for public and quasi-private environmental goods in Switzerland. Population and Environment, 32(1), 42-65. http://dx.doi.org/10.1007/s11111-010-0116-y

MMA. (2012). O que o brasileiro pensa do meio ambiente e do consumo sustentável: Pesquisa nacional de opinião: principais resultados. Rio de Janeiro: Ministério do Meio Ambiente, Secretaria de Articulação Institucional e Cidadania Ambiental.

Mohai, P., \& Bryant, B. (1998). Is there a "race" effect on concern for environmental quality? Public Opinion Quarterly, 62(4), 475-505. http://dx.doi.org/10.1086/297858

Nawrotzki, R., Diaconu, M., \& Pittman, S. (2009). Climate-Change-Induced human migration: The necessity of collective global action. Global Studies Journal, 2(1), 43-57.

Nawrotzki, R. J. (2012). The Politics of Environmental Concern: A Cross-National Analysis. Organization \& Environment, 25(3), 286-307. http://dx.doi.org/10.1177/1086026612456535

Nawrotzki, R. J., Hunter, L. M., \& Dickinson, T. W. (2012). Rural livelihoods and access to natural capital: Differences between migrants and non-migrants in Madagascar. Demographic Research, 26, 661-699. http://dx.doi.org/10.4054/DemRes.2012.26.24

Nawrotzki, R. J., \& Pampel, F. C. (2012). Cohort change and the diffusion of environmental concern: A $\begin{array}{lllll}\text { cross-national analysis. Population and } & \text { Environment, }\end{array}$ http://dx.doi.org/10.1007/s11111-012-0182-4

Nixon, H., \& Saphores, J. D. M. (2009). Information and the decision to recycle: results from a survey of US households. Journal of Environmental Planning and Management, 52(2), 257-277. http://dx.doi.org/10.1080/09640560802666610

Nunnally, J. C. (1978). Psychometric theory. New York: McGraw-Hill.

Paczynska, A. (2005). Inequality, political participation, and democratic deepening in Poland. East European Politics and Societies, 19(4), 573-613. http://dx.doi.org/10.1177/0888325405274929

Pampel, F. C., \& Hunter, L. M. (2012). Cohort Change, Diffusion, and Support for Environmental Spending in the United States. American Journal of Sociology, 118(2), 420-448. http://dx.doi.org/10.1086/666506

Pasternak, S. (2006). São Paulo e suas favelas Revista do Programa de Pós Graduação em Arquitetura e Urbanismo da FAU/USP (Vol. 27, pp. 176-197). São Paulo, Brazil.

R Core Team. (2013). R: A language and environment for statistical computing. Vienna, Austria: R Foundation for Statistical Computing. Retrieved from http://www.R-project.org/

Rice, A., \& Bostrom, G. (2011). Measurements of carbon dioxide in an Oregon metropolitan region. Atmospheric Environment, 45(5), 1138-1144. http://dx.doi.org/10.1016/j.atmosenv.2010.11.026

Rohrschneider, R. (1990). The roots of public-opinion toward new social-movements - An empirical-test of competing explanations. American Journal of Political Science, 34(1), 1-30. http://dx.doi.org/10.2307/2111509 
Schultz, P. W., Gouveia, V. V., Cameron, L. D., Tankha, G., Schmuck, P., \& Franek, M. (2005). Values and their relationship to environmental concern and conservation behavior. Journal of Cross-Cultural Psychology, 36(4), 457-475. http://dx.doi.org/10.1177/0022022105275962

Shriver, T. E., \& Webb, G. R. (2009). Rethinking the Scope of Environmental Injustice: Perceptions of Health Hazards in a Rural Native American Community Exposed to Carbon Black. Rural Sociology, 74(2), 270-292. http://dx.doi.org/10.1111/j.1549-0831.2009.tb00392.x

Subramanian, S. V., Jones, K., Kaddour, A., \& Krieger, N. (2009). Revisiting Robinson: The perils of individualistic and ecologic fallacy. International Journal of Epidemiology, 38(2), 342-360. http://dx.doi.org/10.1093/ije/dyn359

Torres, H., Alves, H., \& De Oliveira, M. A. (2007). Sao Paulo peri-urban dynamics: Some social causes and environmental consequences. Environment and Urbanization, 19(1), 207-223. http://dx.doi.org/10.1177/0956247807076784

Uhlenberg, P. (2006). Demography of aging. In D. Poston \& M. Micklin (Eds.), Handbook of Population (pp. 143-167). New York: Springer Publishers.

UNFCCC. (1998). Kyoto protocol to the United Nations Framework Convention on Climate Change. Washington, D.C.: United Nations Framework Convention on Climate Change. Retrieved June 19, 2011, from http://unfecc.int/resource/docs/convkp/kpeng.pdf

UNFCCC. (2008). Report of the Conference of the Parties on its thirteenth session, held in Bali from 3 to 15 December 2007. Washington, D.C.: United Nations Framework Convention on Climate Change. Retrieved June 19, 2011, from http://unfecc.int/resource/docs/2007/cop13/eng/06.pdf

Uyeki, E. S., \& Holland, L. J. (2000). Diffusion of pro-environment attitudes? American Behavioral Scientist, 43(4), 646-662. http://dx.doi.org/10.1177/00027640021955478

Whittaker, M., Segura, G. M., \& Bowler, S. (2005). Racial/ethnic group attitudes toward environmental protection in California: Is "environmentalism" still a white phenomenon? Political Research Quarterly, 58(3), 435-447.

Wickham, H. (2009). ggplot2: Elegant graphics for data analysis. New York: Springer. http://dx.doi.org/10.1007/978-0-387-98141-3

Xiao, C. Y., \& Dunlap, R. E. (2007). Validating a comprehensive model of environmental concern cross-nationally: A US-Canadian comparison. Social Science Quarterly, 88(2), 471-493. http://dx.doi.org/10.1111/j.1540-6237.2007.00467.x

\section{Notes}

Note 1. Module 1 contains information on characteristics of the household and its surrounding environment as well as questions on environmental perception, values, and behavior. Module 2 includes socio-demographic information of household members. Module 3 provides information on employment and income of working-age adults. Module 4 contains information on spatial mobility of the household unit. Module 5 includes information on the family and community. Respondents' health status is the focus of Module 6, while education status is surveyed in Module 7.

Note 2. The environmental concern scale shows a relatively low Cronbach's alpha (Cronbach, 1951) value $($ alpha $=.307)$. Although not ideal, we believe that a low alpha value is acceptable in our specific case for a number of reasons:

(1) Number of items: Chronbach's alpha is dependent on the number of items, with small number of items usually producing low alpha values (Drost, 2011; Nunnally, 1978). Unfortunately, only four environmental concern items are available in our data set and this small number is, in part, responsible for the low observed alpha value.

(2) Multidimensionality: Cronbach's alpha is most useful for estimating reliability for item-specific variance in a unidimensional scale (Cortina, 1993). However, it is not well suited to evaluate scales that attempt to represent the domain of a multidimensional construct. As such, the low alpha does not necessary mean that the domain of environmental concern is not captured appropriately, but rather that the latent construct is broad and multifaceted. 
(3) Coverage of theoretical construct domain: If we intend to measure a relatively broad theoretical construct (such as environmental concern), any individual item is necessarily narrower defined or more specific than the construct. If all items were highly consistent, therefore highly correlated, the resulting scale would be narrow and specific and could not be considered a valid representation of the broader construct because only a narrow part of the construct would be covered by the scale (Cattell \& Kline, 1977, cited in Kline, 2000). Moreover, the high correlation would suggest redundancy of the item content, and in such a case it might be best to use only one item to represent all four items in the analysis. As such, a high alpha level would not be desired in our case since it would indicate redundancy as well as insufficient coverage of the theoretical construct domain.

(4) Valid measure of latent construct: For our environmental concern scale it is not the average correlation between the items (measured by Cronbach's alpha) that is important, but rather the correlation of each item with the latent (unmeasured) construct of environmental concern. For example, if people in our study would have responded to the environmental concern questions by always choosing the highest number without even reading the question, the variables would be highly correlated with each other, but would be essentially uncorrelated with the latent construct of environmental concern. To avoid redundancy and maximize the information content captured by a scale, the contributing items should ideally be highly correlated with the latent construct but only little correlated with each other, inevitably producing a low alpha value (c.f., Kline, 2000). However, because the correlation between each individual item and the latent construct cannot be measured directly, we employ theory to justify the inclusion of the items in the scale (c.f., Bollen, 1989; Drost, 2011). All four items demonstrate content validity and appear to represent different facets of the domain of environmental concern. For example, a household that scores high on all four questions (producing a high value on the additive scale) can be considered more environmentally concerned than a household that scores low on all four questions (low value on the additive scale).

(5) Relativity of alpha level: Lance et al. (2006) have pointed out that the frequently cited cutoff points for Cronbach's alpha values constitute an "urban legend." The seminal work by Nunnally (1978) clearly recognized that a single reliability standard should not be applied universally. Rather "what a satisfactory level of reliability is depends on how a measure is being used" (Nunnally, 1978, p. 245). In our exploratory research effort, the goal was to use all the available information to best capture the broad and multifaceted latent construct of environmental concern, even if this scale shows a low alpha value, for the reasons mentioned above.

\section{Copyrights}

Copyright for this article is retained by the author(s), with first publication rights granted to the journal.

This is an open-access article distributed under the terms and conditions of the Creative Commons Attribution license (http://creativecommons.org/licenses/by/3.0/). 